\title{
QUADRATIC INTERPOLATION AND SOME OPERATOR INEQUALITIES
}

\author{
MING FAN
}

Abstract. We investigate some properties of Hilbert spaces and bounded linear operators under quadratic interpolation in both qualitative and quantitative ways. Interpolation type, reiteration, interpolation methods associated with quasi-power function parameters, nonlinear commutator estimates, and interpolation of certain operators and spectral properties are under consideration.

Mathematics subject classification (2010): Primary 46B70, 46M35; Secondary 46C05, 47A10, 47A63. Keywords and phrases: Interpolation type, quadratic interpolation, quasi-power parameter, reiteration, spectrum.

\section{REFERENCES}

[1] E. Albrecht, Spectral interpolation, in: Operator Theory: Advances and Applications 14, 13-37, Birkhäuser, Basel, 1984.

[2] E. Albrecht \& V. Müller, Spectrum of interpolated operators, Proc. A. M. S., 129 (2001), 807814.

[3] Y. AMEuR, The Calderón problem for Hilbert couples, Ark. Mat., 41 (2003), 203-231.

[4] Y. Ameur, A new proof of Donoghue's interpolation theorem, J. Funct. Space Appl., 2 (2004), 253265.

[5] Y. AmeUR, A note on a theorem of Sparr, Math. Scand., 94 (2004), 155-160.

[6] J. Banas \& K. Goebel, Measures of noncompactness in Banach spaces, Lect. Pure Appl. Math., 60 (2000).

[7] J. BERGH \& J. LÖFströM, Interpolation spaces, Grundlehren Math. Wiss. 223, Springer-Verlag, Berlin/Heidelberg/New York, 1976.

[8] F. Cobos, L. M. FernándeZ-Cabrera \& A. Martinez, Abstract $K$ and $J$ spaces and measure of non-compactness, Math. Nachr., 280 (2007), 1698-1708.

[9] W. F. JR. Donoghue, The interpolation of quadratic norms, Acta Math., 118 (1967), 251-270.

[10] W. F. JR. Donoghue, Monotone matrix functions and analytic continuation, Grundlehren Math. Wiss. 207, Springer-Verlag, Berlin/Heidelberg /New York, 1974.

[11] M. FAn \& S. KaIJSER, Complex interpolation with derivatives of analytic functions, J. Funct. Anal., 120 (1994), 380-402.

[12] M. FAN, Complex interpolation functors with a family of quasi-power function parameters, Studia Math., 111 (1994), 283-305.

[13] M. FAn, Commutator estimates for interpolation scales with holomorphic structure, Complex Anal. Oper. Theory, 4 (2010), 159-178.

[14] C. Foias, S-C. Ong \& P. Rosenthal, An interpolation theorem and operator ranges, Int. Eq. Op. Th., 10 (1987), 802-811.

[15] B. JAWERTH, R. RochBerg \& G. Weiss, Commutators and other second order estimates in real interpolation theory, Ark. Mat., 24 (1986), 191-219.

[16] J. PeETRE, On interpolation functions I-III, Acta. Sci. Math. (Szeged), 27 (1966), 167-171; 29 (1968), 91-92; 30 (1969), 235-239. 